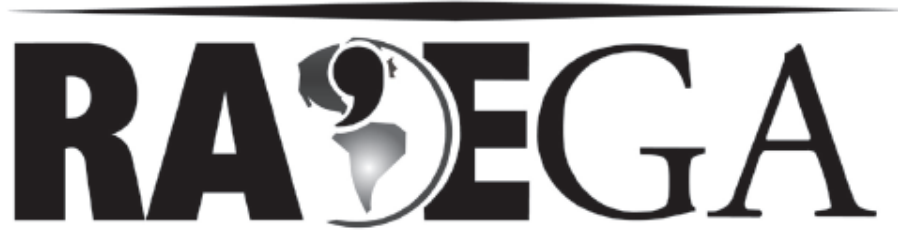

O ESPAÇO GEOGRÁFICO EM ANÁLISE

\title{
ESPACIALIZAÇÃO DA PERDA DE SOLO POR EROSÃO LAMINAR NA MICROBACIA DO RIO CAMPINAS, JOINVILLE SC
}

SPATIALIZATION OF SOIL LOSS BY SHEET EROSION IN THE WATERSHED OF CAMPINAS RIVER, JOINVILLE SC

\author{
Rafael Zoboli GUIMARÃES ${ }^{1}$ \\ Christel LINGNAU ${ }^{2}$ \\ Nivaldo Eduardo RIZZI ${ }^{3}$ \\ Richardson Guenther SCHEICHI ${ }^{4}$ \\ Rita de Cassia BIANCHI ${ }^{5}$
}

\section{RESUMO}

Com intuito de identificar as áreas mais suscetíveis aos processos erosivos, foi aplicada a equação universal de perda de solo (EUPS) em ambiente SIG na microbacia do Rio Campinas, tributário do Rio Cubatão do Norte, no município de Joinville, SC. O mapa de estimativa de perda anual de solo por erosão laminar demonstrou taxas de erosão de 0 a 355 t.ha $^{-1}$.ano- ${ }^{-1}$, divididos em 6 classes de perda de solo. As classes predominantes de perda de solo foram de 0 a 1 tha ${ }^{-1} \cdot$ ano $^{-1}(70,5 \%)$ e $1-3$ t.ha $^{-1} \cdot$ ano $^{-1}(22,8 \%)$. O grande percentual de áreas cobertas por floresta nativa e florestas plantadas foram os responsáveis

\footnotetext{
${ }^{1}$ Eng. Ambiental, Mestrando em Eng. Florestal pela Universidade Federal do Paraná, UFPR, Curitiba, PR, Brasil-rzguimaraes@gmail.com

2 Eng. Florestal, Prof Dra . Departamento de Engenharia e Tecnologia Florestal da Univerdade Federal do Paraná, UFPR,- lingnau@ufpr.br

${ }^{3}$ Eng. Florestal, Prof Dr. Do Departamento de Engenharia e Tecnologia Florestal da Universidade Federal do Paraná, UFPR - niva@ufpr.br

4 Eng. Florestal, Mestrando em Eng. Florestal pela Universidade Federal do Paraná, UFPR, engrichardson@gmail.com

5 Eng. Florestal, Mestranda em Eng. Florestal pela Universidade Federal do Paraná, UFPR, risobiachi@yahoo.com.br
} 
por manter as taxas de erosão baixas. As estradas florestais, áreas urbanizadas/solo exposto e áreas cobertas por capoeira, sob argissolos, com declividades acentuadas, apresentaram as maiores taxas de perda de solo por erosão laminar.

Palavras-chave: Erosão laminar; Perda de Solo; EUPS.

\section{ABSTRACT}

In order to identify the most susceptible erosion areas, we applied the universal soil loss equation (USLE) in a GIS environment for the Campinas river watershed, tributary to North Cubatao River, in Joinville, SC. The map of annual estimation of soil loss due sheet erosion showed erosion rates from 0 to 355 t.ha $^{-1}$.year ${ }^{-1}$, divided into six classes of soil loss. The predominant classes of soil loss were 0-1 t.ha . $^{-1}$ year $^{-1}(70.5 \%)$ and 1-3 t.ha $^{-1}$.year ${ }^{-1}$ (22.8\%). The high percentage of areas covered by native forest and plantations were responsible for maintaining low rates of soil erosion. Forest roads, urbanized areas/bare soil and areas covered by "capoeira" vegetation, in argisols, with steep slopes, had the highest rates of soil loss by erosion.

Key-words: Sheet erosion; soil loss; USLE.

\section{INTRODUÇÃO}

Os estudos de qualidade de água superficial em bacias hidrográficas tornam-se bastante complexos pelo fato de que os parâmetros de qualidade podem ser influenciados por vários fatores, como as formas de uso e ocupação do solo, tipos de rochas, de solos e condições climáticas. Portanto, para interpretar as alterações na qualidade de água registradas ao longo de um determinado trecho de rio e/ou espaço de tempo, é imprescindível a caracterização do meio físico das áreas de contribuição da bacia hidrográfica e dos processos que culminaram nessas alterações.

A erosão hídrica laminar, definida como a remoção homogênea da porção superficial de solo, é um dos processos que influenciam a qualidade da água de um rio. O uso e ocupação do solo conduzido de forma inadequada, principalmente em atividades agropecuárias e silviculturais sem controle, associados aos fatores naturais (chuva, declividade, tipo de solo), aceleram a degradação do solo, desagregando partículas que são transportadas à rede de drenagem (SANTOS et al., 2010 p. 116), promovendo a elevação da concentração de materiais em suspensão e dos índices de turbidez nos cursos de água, diminuindo a penetração de raios solares, com consequente diminuição nos processos fotossintéticos e produção de oxigênio. Alem disso, 
as áreas mais susceptíveis aos processos erosivos apresentam maior potencial ao carreamento de poluentes para a rede hidrográfica, como nutrientes, materiais orgânicos e agrotóxicos associados as partículas do solo, deteriorando a qualidade das águas (OKI, 2002; SANTOS et al., 2003; CAVICHIOLO, 2005).

A identificação das áreas mais susceptíveis aos processos erosivos e sua caracterização quanto à composição do solo e as atividades realizadas nas bacias hidrográficas, constituem importante ferramenta para subsidiar as discussões sobre a degradação de cursos de água.

Para estudar este tipo de fenômeno dispõe-se de métodos diretos, baseados na coleta do material erodido, em campos experimentais e/ou em laboratório, ou ainda de métodos indiretos, por meio de modelagem matemática. Estes modelos podem ser associados às técnicas de geoprocessamento, que permitem análises espaciais do fenômeno, visando o planejamento racional do uso e ocupação do solo e na exposição das áreas que necessitam de adoção de práticas de controle da erosão (HELFER et al., 2003 p. 2).

A equação universal de perda de solo, inicialmente criada para aplicação no setor agrícola (Wischmeier \& Smith, 1965), e que passou por algumas modificações para ampliar sua aplicabilidade (Lombardi Neto \& Bertoni, 1975; Bertoni \& Lombardi Neto, 1990; Renard et al., 1991) é um dos métodos de estimativa de perda de solo indireto mais empregado atualmente, como pode ser observados em vários trabalhos científicos (MANNINGEL et al., 2002; OKAFIORI, 2002; HELFER et al., 2003; HILU, 2003; OKA-FIORI et al., 2004; CORREA et al., 2007; AVANZI et al., 2008; SANTOS et al., 2010; SILVA et al., 2010)

Este trabalho teve como objetivo estimar a perda de solo por erosão laminar por meio da Equação Universal de Perda de Solo (EUPS) na microbacia do Rio Campinas, município de Joinville, SC, para subsidiar futuras discussões a respeito do monitoramento de qualidade de água nas áreas de reflorestamento de Pinus. 


\section{MATERIAL E METODOS}

A microbacia experimental utilizada neste estudo está localizada na região nordeste de Santa Catarina, no município de Joinville, com altitude média de 800 metros (Figura 1). O reflorestamento de pinus localiza-se no alto curso do Rio Cubatão do Norte, a oeste da escarpa da Serra do Mar, inserida principalmente na microbacia do Rio Campinas, tributário do Rio Cubatão do Norte. A microbacia do Rio Campinas possui área total de 3716,76 ha, cobertas principalmente por floresta (70,3\%) e plantio de pinus (24,3\%) (Figura 2$)$.
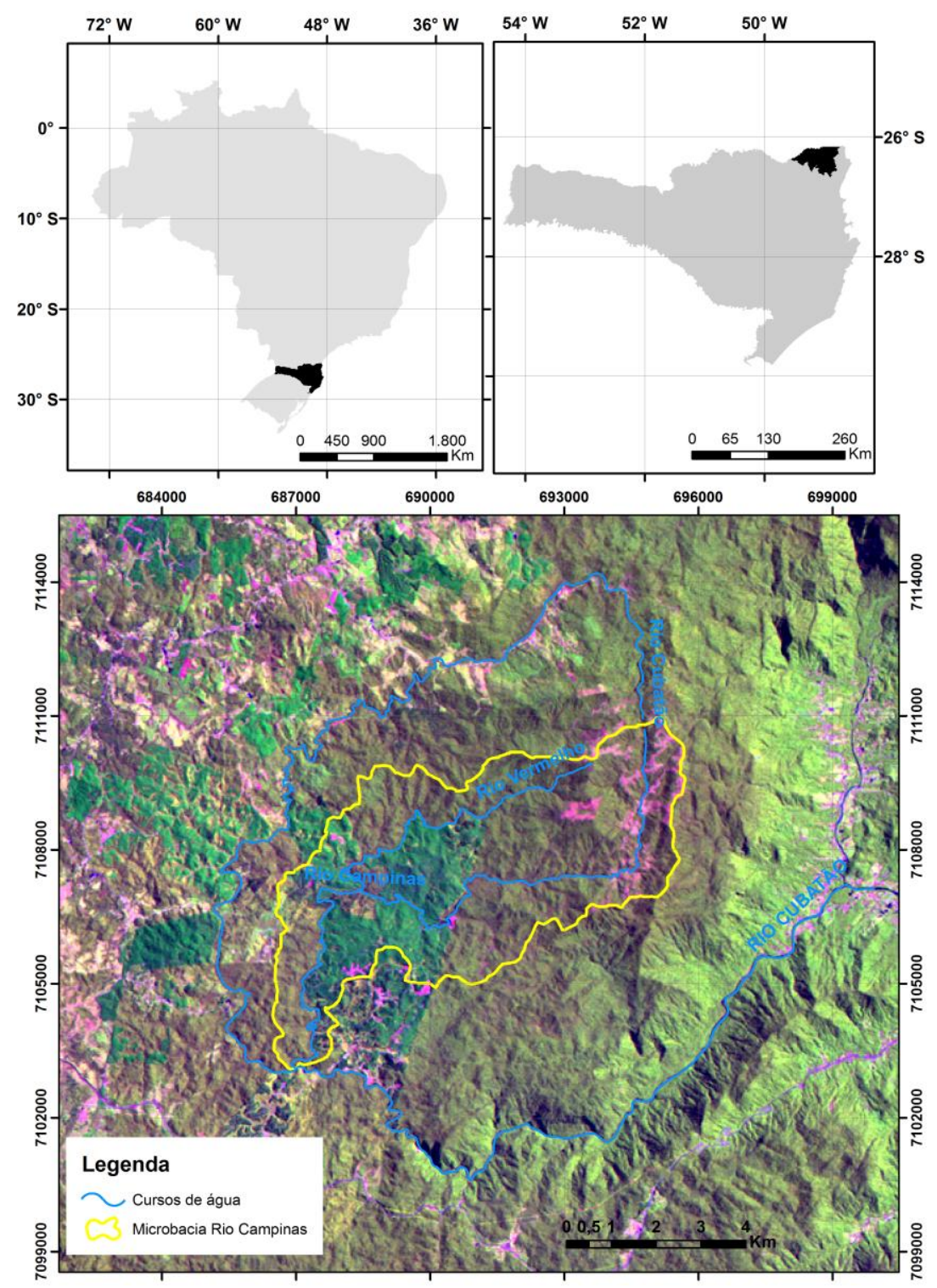

Figura 1: Localização da área de estudo a nível nacional, estadual e regional 


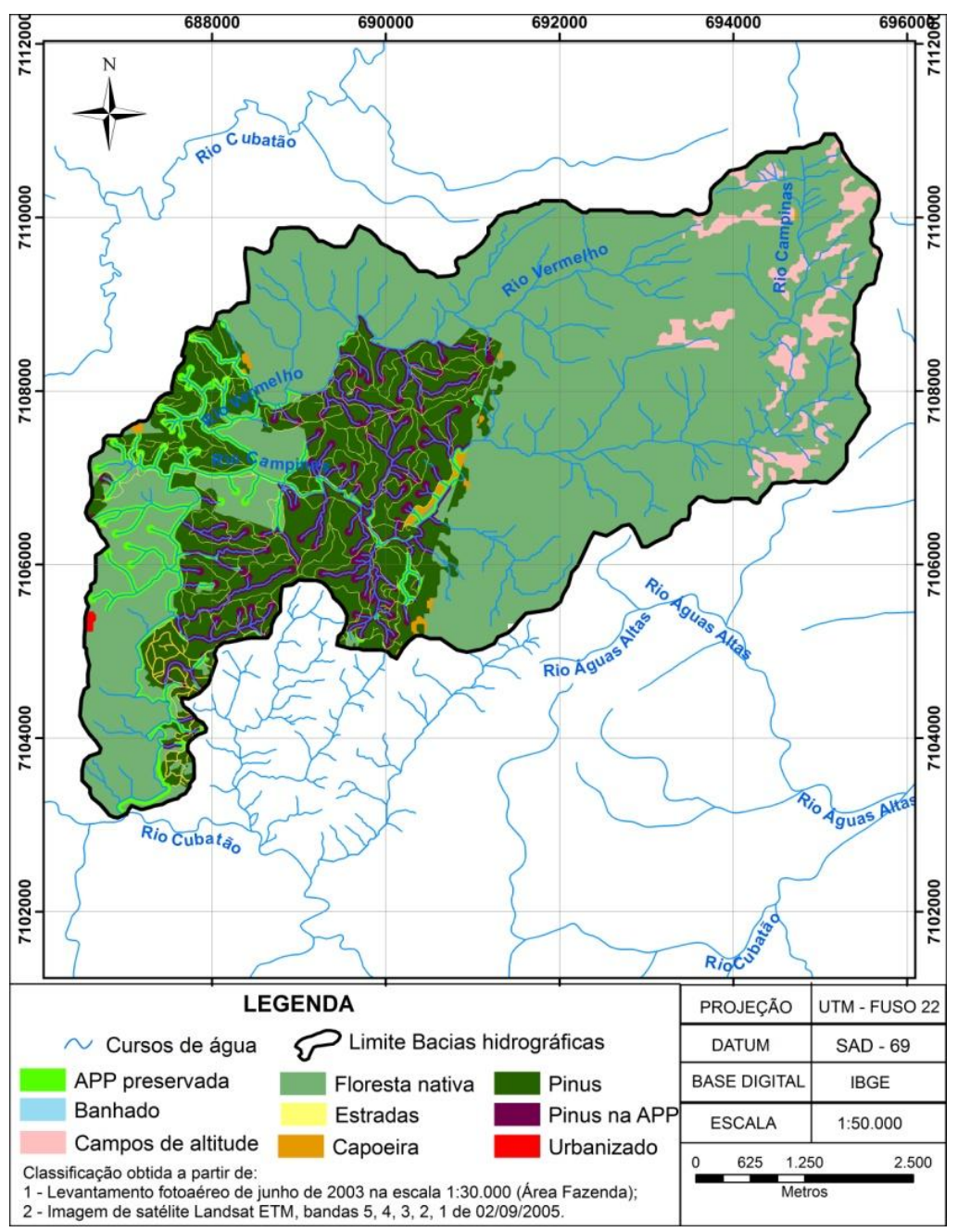

Figura 2: Mapa de uso de solo da microbacia do Rio Campinas.

Na região da microbacia do Rio Campinas foram encontrados dois tipos climáticos segundo a classificação de Köppen: o clima temperado chuvoso e moderadamente quente, úmido em todas as estações, com verão quente (Cfa), e o clima chuvoso e moderadamente quente, úmido em todas as estações, com verão moderadamente quente (Cfb) (GONÇALVES, et al, 2006 p. 15 a 22). Portanto, o tipo climático ocorrente na região é uma transição entre Cfa, (da porção central da microbacia em direção leste/sudeste, e Cfb, da porção central da microbacia em direção nordeste. A precipitação média anual na região gira em torno de 1900 a 2300 mm, com períodos mais chuvosos na primavera e verão e máximas nos meses de janeiro e fevereiro, e menor pluviosidade no outono e inverno, com mínimas em junho e julho. Porém esta variação não é acentuada entre estes períodos, podendo ocorrer precipitações intensas em qualquer época do ano (GONÇALVES, et al. 2006 p. 15 a 22). 
Para quantificar a perda de solo por erosão laminar, utilizou-se a Equação Universal de Perdas de Solo (EUPS) desenvolvida pelo Serviço de Pesquisa Agrícola (ARS) do Departamento de Agricultura dos Estados Unidos (USDA), W. H. Wischmeier e D. D. Smith (1965), sendo uma das mais aceitas e utilizadas para estimar as perdas anuais de solo. A EUPS é definida por:

$$
A=R^{*} K^{*} L^{*} S^{*} C^{*} P
$$

onde:

$\mathrm{A}=$ estimativa de perda de solo $\left(\mathrm{t} \mathrm{ha}^{-1}\right.$ ano $\left.{ }^{-1}\right)$;

$\mathrm{R}=$ erosividade da chuva (MJ $\mathrm{mm} \mathrm{ha}^{-1} \mathrm{~h}^{-1}$ ano ${ }^{-1}$ );

$\mathrm{K}=$ erodibilidade do solo ( $\mathrm{t}$ ha $\mathrm{h} \mathrm{ha} \mathrm{MJ}^{-1} \mathrm{~mm}^{-1}$ );

$\mathrm{L}=$ comprimento de rampa (adimensional);

$\mathrm{S}=$ declividade (adimensional);

$\mathrm{C}=$ uso e manejo do solo (adimensional); e

$\mathrm{P}=$ práticas conservacionistas (adimensional).

A perda de solo foi calculada de acordo com a sistemática apresentada na Figura 3. Confeccionou-se cinco mapas correspondendo aos fatores erosividade $(R)$, declividade $(S)$, comprimento de vertente $(L)$, erodibilidade $(K)$ e uso e manejo do solo (CP). Obtidos todos os fatores, a equação de perda de solo foi calculada multiplicando pares de mapas, até que todos os fatores tenham sido multiplicados. O produto final foi o mapa de estimativa de perdas anuais de solo.

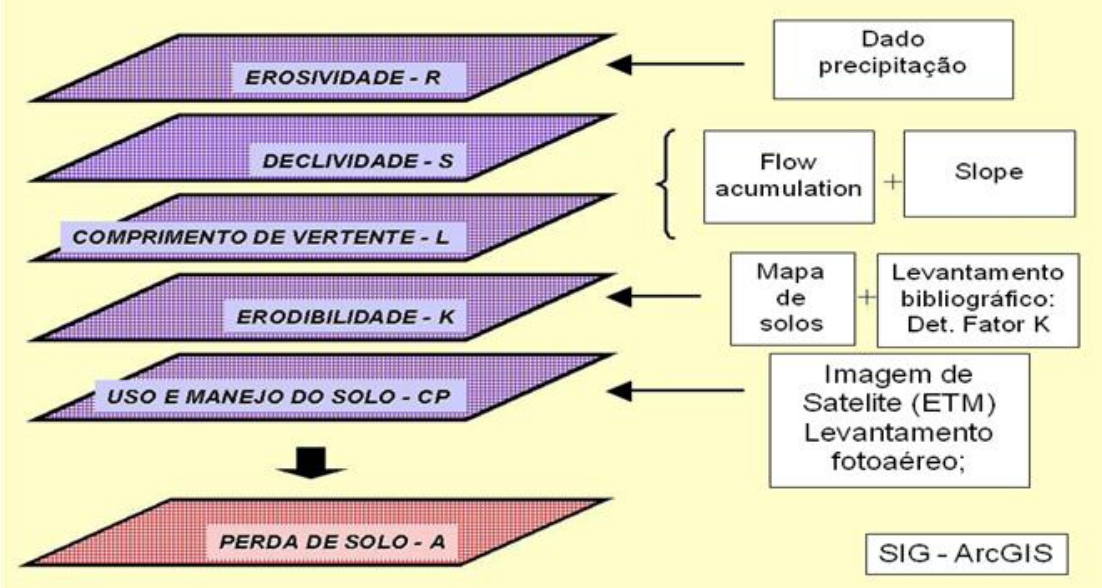

Fonte: Modificado de HELFER, et al. (2003).

Figura 3: Sistemática de integração dos fatores da EUPS. 
O fator R é um índice numérico que expressa a capacidade da chuva em provocar erosão em uma área sem proteção (Bertoni \& Lombardi Neto, 1990 p. 250). Para o cálculo do Fator $R$ utilizou-se a equação proposta por Lombardi Neto e Moldenhauer (apud Bertoni e Lombardi Neto, 1990) para determinação de um valor médio do índice de erosividade por meio da relação entre a média mensal e a média anual de precipitação:

$$
E \mathrm{I}=67,355\left(\mathrm{r}^{2} / \mathrm{P}\right)^{0,85}
$$

onde:

$\mathrm{EI}=$ média mensal do índice de erosividade $\left(\mathrm{MJ} \mathrm{mm} \mathrm{ha}^{-1} \mathrm{~h}^{-1}\right)$;

$r$ = média do total mensal de precipitação $(\mathrm{mm})$;

$\mathrm{P}=$ média do total anual de precipitação $(\mathrm{mm})$.

$\mathrm{O}$ índice de erosão médio anual (fator $\mathrm{R}$ ) é a soma dos valores mensais dos índices de erosão (El). Para o cálculo do fator $R$ foram utilizados os dados de precipitação pluviométrica da Estação Meteorológica UDESC-UNIVILLE de 1996 a 2007 (Figura 1 e Tabela 1). Optou-se pela Estação Meteorológica da UDESC-UNIVILLE por apresentar uma série histórica maior e mais completa, comparada com as demais estações que estão destacadas na Figura 1. Para espacialização do índice de erosividade anual utilizou-se o mapeamento de distribuição de precipitação anual da Bacia Hidrográfica do Rio Cubatão do Norte (OLIVEIRA, 2006 p. 117), onde foi empregado o valor do Fator $R$ do ano que apresentou precipitação total correspondente aos índices de cada isoieta.

O fator erodibilidade do solo $(\mathrm{K})$, segundo Bertoni \& Lombardi Neto (1990 p. 258), tem seu valor quantitativo determinado experimentalmente em parcelas unitárias, sendo expresso como a perda de solo $(A)$ por unidade de índice de erosão da chuva (EI), e varia de acordo com as propriedades do solo. $\mathrm{Na}$ área em estudo ocorrem dois tipos de solo, Argissolo Amarelo Distrófico e Cambissolo Háplico Alumínico, conforme mapeamento do Instituto Brasileiro de Geografia e Estatística em escala 1:100.000 (IBGE, 2002). Os valores de erodibilidade dos solos ocorrentes na área em estudo foram obtidos na literatura, em trabalhos cujas áreas de estudo apresentavam características semelhantes. 
Os fatores cobertura do solo $(C)$ e práticas conservacionistas $(P)$ são tratados separadamente quando se trabalha com bacias hidrográficas pequenas e quando o uso agrícola possui grande expressividade em área ocupada, de maneira que as praticas conservacionistas influenciam nas taxas de perda de solo (HELFER et al., 2003 p.8). Como a ocupação da microbacia do Rio Campinas caracteriza-se principalmente por áreas preservadas (Floresta Ombrófila Montana e Alto-montana) e atividades silviculturais, sem presença de práticas agrícolas (Figura 2), os fatores cobertura de solo e práticas conservacionistas foram considerados em conjunto (CP), assim como muitos autores (OKA-FIORI, 2002; HELFER et al., 2003; MARTINS, 2005; AVANCl et al., 2008; SILVA et al., 2010).

A classificação de uso e ocupação de solo foi realizado a partir de imagens de restituição aerofotogramétrica de junho de 2003 na escala de 1:30.000, correspondendo a área do reflorestamento de pinus, fornecida pela empresa que administra a fazenda reflorestada, e imagem de satélite Landsat ETM, bandas 5, 4, 3, 2 e 1 de 02/09/2005 na escala 1:50.000, abrangendo demais áreas da microbacia do Rio Campinas. Da mesma forma que o fator $\mathrm{K}$, os valores do fator CP para as classes de uso e ocupação de solo da microbacia foram obtidos na literatura.

O fator topográfico LS é a relação esperada de perdas de solo por unidade de área em um declive qualquer em relação à perda de solo correspondente de uma parcela de $25 \mathrm{~m}$ de comprimento com $9 \%$ de declive (LOMBARDI NETO \& BERTONI, 1990 p. 259). Para o cálculo do fator LS utilizou-se a metodologia proposta pelo GIS Assessment Service, que obtêm os valores do fator comprimento de rampa $(L)$ e em seguida relaciona com o mapa de declividade (fator S), através da fórmula (AZIM-ZADE, 2010 p. 12):

$$
L S=\left(\frac{\text { FlowAccumulation } * \text { cellzise }}{22,13}\right)^{0,6} *\left(\frac{\text { Sen }(\text { slope } * 0,011745)}{0,09}\right)^{1,2}
$$




\section{RESULTADOS E DISCUSSÕES}

A erosão é causada por forças ativas, decorrente das características da chuva, declividade, comprimento do declive do terreno e capacidade que tem o solo de absorver água, e por forças passivas, como a resistência que exerce o solo à ação da água e a densidade da cobertura vegetal (BERTONI \& LOMBARDI NETO, 1990). Esses fatores foram avaliados na microbacia do Rio Campinas sob a ótica da equação universal de perda de solo (EUPS), para identificar as áreas mais suscetíveis à erosão, visando futuramente subsidiar as discussões a respeito da influência da atividade de silvicultura sobre a qualidade de água superficial.

A Tabela 1 apresenta os dados pluviométricos da estação meteorológica UDESC-UNIVILLE utilizados para o cálculo do fator erosividade $(R)$. O fator $R$ foi calculado para cada ano de registro pluviométrico disponível e também utilizando as médias mensais e anuais para o período de 1996 a 2007. Para a espacialização do fator $R$ na área em estudo, tomou-se como base o mapa de distribuição pluviométrica anual da Bacia Hidrográfica do Rio Cubatão do Norte (OLIVEIRA, 2006 p. 117), conforme já descrito nos materiais e métodos.

Tabela 1: Dados de precipitação pluviométrica da Estação UDESC-UNIVILLE e valores calculados do Fator R.

\begin{tabular}{c|cccccccccccc|c}
\hline Mês & 1996 & 1997 & 1998 & 1999 & 2000 & 2001 & 2002 & 2003 & 2004 & 2005 & 2006 & 2007 & Média \\
\hline jan & 418,0 & 364,6 & 492,8 & 458,7 & 379,1 & 277,2 & 340,1 & 294,5 & 231,2 & 437,9 & 280,3 & 335,9 & 359,2 \\
fev & 281,5 & 169,3 & 487,7 & 382,5 & 262,9 & 599,4 & 122,3 & 294,1 & 239,9 & 80,2 & 300,2 & 256,2 & 289,7 \\
mar & 428,5 & 193,3 & 300,4 & 319,1 & 116,7 & 419,4 & 273,2 & 228,2 & 128,7 & 147,7 & 225,9 & 184,7 & 247,2 \\
abr & 126,0 & 23,8 & 226,2 & 104,5 & 12,1 & 173,6 & 145,4 & 54,9 & 213,1 & 175,3 & 113,2 & 112,0 & 123,3 \\
mai & 17,3 & 95,8 & 27,7 & 99,5 & 18,4 & 192,3 & 95,9 & 52,9 & 130,1 & 121,9 & 22,9 & 220,0 & 91,2 \\
jun & 251,0 & 76,9 & 77,2 & 96,0 & 62,1 & 193,4 & 67,5 & 83,5 & 60,9 & 76,6 & 26,3 & 21,9 & 91,1 \\
jul & 165,0 & 70,0 & 160,2 & 280,7 & 51,4 & 181,4 & 56,7 & 69,3 & 175,3 & 159,1 & 48,3 & 76,5 & 124,5 \\
ago & 65,0 & 152,4 & 447,2 & 26,9 & 55,2 & 48,8 & 104,0 & 34,1 & 48,8 & 189,5 & 52,4 & 58,1 & 106,9 \\
set & 221,7 & 146,8 & 154,3 & 167,8 & 195,1 & 247,3 & 215,8 & 113,0 & 138,0 & 248,8 & 150,1 & 107,8 & 175,5 \\
out & 127,6 & 450,5 & 307,1 & 174,1 & 159,5 & 219,2 & 174,3 & 77,4 & 129,9 & 210,5 & 121,1 & 162,5 & 192,8 \\
nov & 131,6 & 451,4 & 125,1 & 267,8 & 198,5 & 144,8 & 174,3 & 99,9 & 110,6 & 209,1 & 448,6 & 174,3 & 211,3 \\
dez & 237,8 & 162,7 & 242,0 & 188,6 & 165,5 & 98,5 & 223,1 & 218,1 & 226,8 & 119,2 & 118,9 & 299,1 & 191,7 \\
\hline Média & 205,9 & 196,5 & 254,0 & 213,9 & 139,7 & 232,9 & 166,1 & 135,0 & 152,8 & 181,3 & 159,0 & 167,4 & 183,7 \\
mensal & & & & & & & & & & & & \\
Total & 2471,0 & 2357,5 & 3047,9 & 2566,2 & 1676,5 & 2795,3 & 1992,6 & 1619,9 & 1833,3 & 2175,8 & 1908,2 & 2009,0 & 2204,4 \\
\hline anual & & & & & & & & & \\
Fator R & 8288,6 & 8626,6 & 6934,6 & 8026,5 & 11526,0 & 7463,8 & 9952,1 & 11867,5 & 10682,5 & 9235,2 & 10325,1 & 9883,0 & 9401,0 \\
\hline
\end{tabular}


A microbacia hidrográfica do Rio Campinas apresenta duas áreas com distribuição de precipitação média anual distintas. A primeira, com menor expressividade em área ocupada, situada a noroeste da microbacia do Rio Campinas, com amplitude de 1900 a $2100 \mathrm{~mm}$, e a segunda, abrangendo a maior porção da área em estudo, na faixa de valores entre 2100 a $2300 \mathrm{~mm}$ (Figura 4). O maior índice de erosividade, $9952 \mathrm{MJ} \mathrm{mm} \mathrm{ha}^{-1} \mathrm{~h}^{-1} \mathrm{ano}^{-1}$, foi encontrado na faixa com menores precipitações, enquanto que na área correspondente a 2100 a $2300 \mathrm{~mm}$ o índice de erosividade encontrado foi de $9235 \mathrm{MJ} \mathrm{mm} \mathrm{ha-1} \mathrm{h}^{-1}$ ano $^{-1}$ (Figura 4). Isso é possível já que a capacidade da chuva em provocar a erosão está relaciona a energia cinética da chuva e sua intensidade máxima em um curto espaço de tempo (30 minutos, por exemplo) (BERTONI \& LOMBARDI NETO, 1990 p. 250). Ou seja, o Fator R não necessariamente será maior nas áreas com maiores pluviosidades médias anuais, mas dependerá de como essa precipitação se distribui ao longo do ano.

Para os mapeamentos temáticos de pedologia e de classificação de uso e ocupação de solo, buscou-se utilizar trabalhos com maior detalhamento possível da área em estudo. O mapa de uso e ocupação de solo foi classificado a partir de imagens em escalas de 1:30.000 e 1:50.000, conforme descrito anteriormente, apresentando um bom nível de detalhamento da área. Porém, para o mapa de solos, o maior nível de detalhamento disponível da área em estudo foi encontrado no mapeamento de classificação de solos do IBGE (2002), em uma escala de 1:100.000, que não constitui uma classificação ideal das tipologias de solo para as dimensões desta microbacia, podendo interferir nos resultados das estimativas de perdas de solo.

Com base no mapa de reconhecimentos dos solos da Folha São Miguel (SG-22-Z-B-II - IBGE, 2002), na microbacia do Rio Campinas ocorrem dois tipos de solo, o Argissolo Amarelo Distrófico, distribuído em $71,3 \%$ da microbacia, e o Cambissolo Háplico Alumínico, abrangendo os demais $28,7 \%$, ocupando principalmente a porção nordeste da área em estudo (Figura 5).

Os valores dos índices de erodibilidade (Fator K) foram obtidos na literatura. Nos trabalhos consultados, não foram encontrados valores do fator $\mathrm{K}$ para Cambissolos de subordem Háplico, mas Bertol et al. (2002 p. 1 a 8) 
determinaram o índice de erodibilidade para um Cambissolo Húmico Alumínico, com dados experimentais de perda de solos obtidos sob condições de chuva natural, no período de 1989 a 1998, em Lages, no planalto Catarinense. Encontraram valores de erodibilidade entre 0,0105 a $0,0121 \mathrm{t}$ ha $\mathrm{h} \mathrm{ha}^{-1} \mathrm{MJ}^{-1}$ $\mathrm{mm}^{-1}$ no período de primavera-verão e de 0,0132 e 0,0220 $\mathrm{t}$ ha h ha ${ }^{-1} \mathrm{MJ}^{-1} \mathrm{~mm}^{-}$ 1 para o outono-inverno. Para valores de erodibilidade médias anuais, estimados por regressão linear simples entre as perdas de solo e as erosividades, os mesmo autores obtiveram o valor de 0,0151 t ha $\mathrm{h} \mathrm{ha}^{-1} \mathrm{MJ}^{-1}$ $\mathrm{mm}^{-1}$, o qual foi empregado para o Cambissolo Háplico Alumínico (Figura 5).

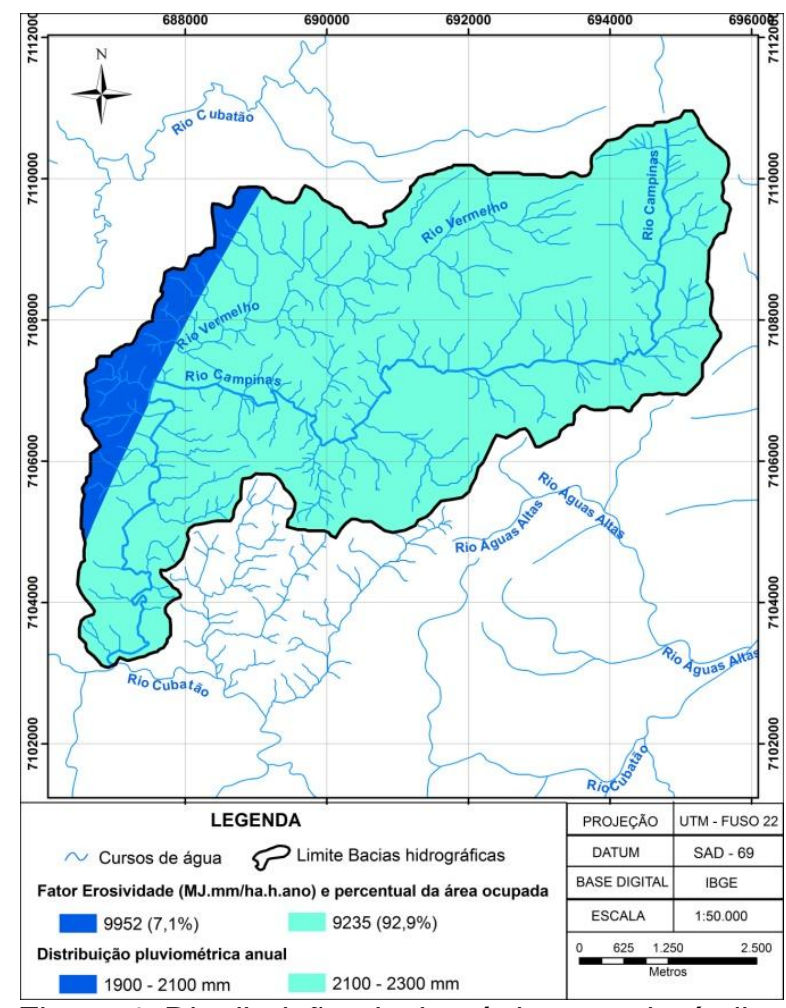

Figura 4: Distribuição pluviométrica anual e índice de erosividade (Fator R) na microbacia do Rio Campinas.

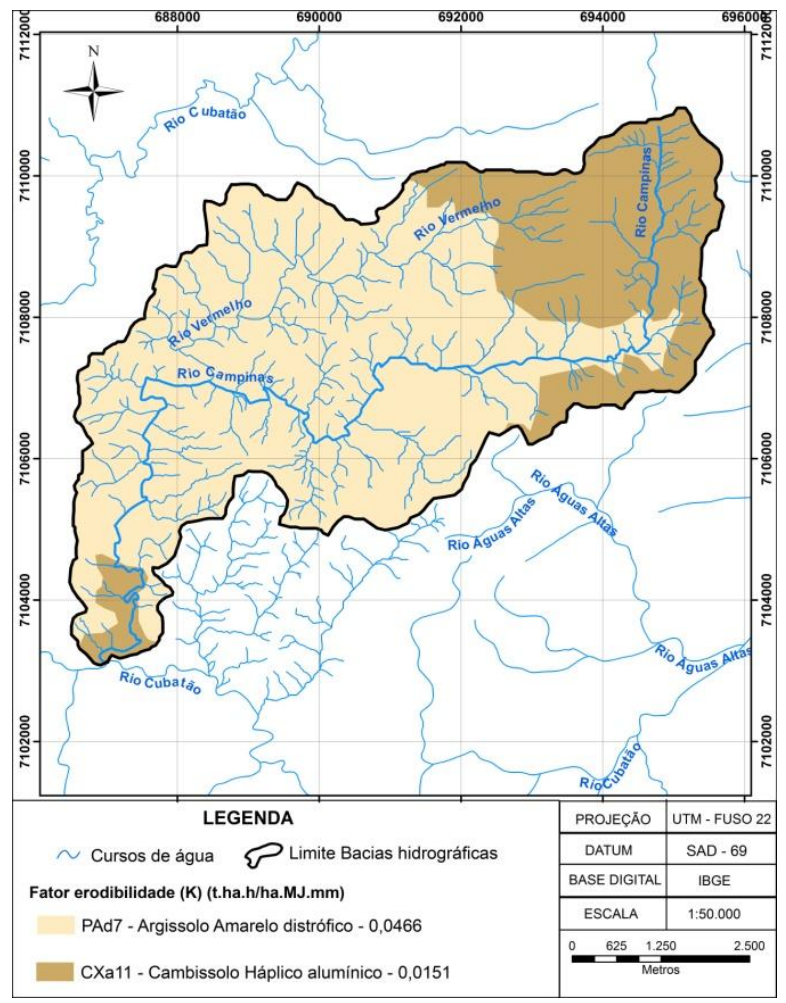

Figura 5: Mapa pedológico e fator erodibilidade $(\mathrm{K})$ na microbacia do Rio Campinas.

Para o Argissolo Amarelo Distrófico utilizou-se o fator erodibilidade determinado por Mannigel et al. (2002 p. 1335 - 1340) pelo método indireto com a equação de Bouyoucos, para os solos do estado de São Paulo. Os autores encontraram valores de erodibilidade de 0,0466 tha h ha-1 $\mathrm{MJ}^{-1} \mathrm{~mm}^{-1} \mathrm{em}$ Horizonte A e $0,0391 \mathrm{t}$ ha h ha-1 $\mathrm{MJ}^{-1} \mathrm{~mm}^{-1}$ em Horizonte B. Neste trabalho empregou-se no cálculo da EUPS o valor de $0,0466 \mathrm{t}$ ha $\mathrm{h} \mathrm{ha}^{-1} \mathrm{MJ}^{-1} \mathrm{~mm}^{-1}$ para os Argissolos Amarelos Distróficos em Horizonte A. Silva (1994, apud CAROLINO DE SÁ, 2004 p. 
692), encontrou índice de erodibilidade para Argissolo Amarelo Eutrófico bem próximo, 0,045 tha h ha-1 $\mathrm{MJ}^{-1} \mathrm{~mm}^{-1}$, demonstrando a consistência e confiabilidade deste valor.

Observa-se que o tipo de solo com maior suscetibilidade a erosão é o Argissolo Amarelo Distrófico, com índice de erodibilidade aproximadamente 3 vezes maior $\left(0,0466 \mathrm{t}\right.$ ha $\left.\mathrm{h} \mathrm{ha}{ }^{-1} \mathrm{MJ}^{-1} \mathrm{~mm}^{-1}\right)$ comparado ao Cambissolo Háplico Alumínico $\left(0,0151 \mathrm{t}\right.$ ha $\left.\mathrm{h} \mathrm{ha} \mathrm{hJ}^{-1} \mathrm{~mm}^{-1}\right)$. Vale Junior et al. (2009 p.7), estudando a erodibilidade dos solos da região do cerrado, afirmaram que os Neossolos Quartzarênicos e os Argissolos foram as classes que apresentaram maiores valores de $\mathrm{K}$, conseqüentemente mais suscetíveis à erosão.

Comparando o mapa pedológico (Figura 5) com o mapa de uso e ocupação de solo (Figura 2) da área em estudo, verifica-se que as áreas de reflorestamento encontram-se, principalmente, sob solos do tipo argissolos, que apresentam maior suscetibilidade a erosão e consequentemente maior potencial de perdas de solo.

Os índices calculados para o fator topográfico LS apresentam valores entre 0 a 48, que foram separados em 9 classes, conforme demonstrado no mapa do Fator LS (Figura 6). 66,1\% da microbacia do Rio Campinas apresentaram valores para o fator LS entre 1 e 2, correspondendo a 2454,30 ha. Quando considerado os valores de 0 a 4 do fator LS, a área de abrangência é de 3379,65 ha, representando 91,2\% do total da superfície da microbacia. Os valores do fator topográfico acima de 8 representam apenas 0,4\% da área em estudo, e estão concentrados principalmente nas áreas mais declivosas, localizadas a nordeste da microbacia do Rio Campinas, região coberta por Floresta Ombrófila Montana e Altomontana preservadas.

Os valores encontrados com maior freqüência para o fator topográfico LS foram baixos já que a área em estudo possui classes de relevo predominantes de ondulado (27,2\%) a forte ondulado (45,3\%). Silva (2003 p.33) estudando métodos informatizados de obtenção do fator LS em uma área com predomínio de relevo suave a suave-ondulado, encontrou valores entre 0 a maior que 50 , com $81,9 \%$ da área enquadrada entre 0 a 4. Silva et al. (2010 p. 146) avaliando a perda de solo na Fazenda experimental da Embrapa no município de São Carlos, encontraram valores do fator LS entre 0 a 40. 
$\mathrm{Na}$ classificação das imagens de levantamento fotoaéreo de 2003 e imagem Landsat ETM 7 de 2005 da microbacia do Rio Campinas, foram encontradas 9 classes de uso e ocupação do solo: (1) Floresta Ombrófila Densa Montana e FOD Alto-montana (mata nativa); (2) campos de altitude; (3) plantio de Pinus taeda e $P$. elliottii; (4) Área de Preservação Permanente (APP) preservada; (5) APP com plantio de pinus (Pinus na APP), em processo de reconversão para floresta nativa; (6) capoeira; (7) área de estradas não pavimentadas (estradas florestais); (8) urbanizado e solo exposto; e (9) área alagável (banhado) (Figura 2). A partir do mapa de uso e ocupação do solo, foram obtidos os valores do fator uso do solo e práticas conservacionista (CP) com base em trabalhos que possuíam a mesma classe de uso e ocupação de solo (Figura 7).

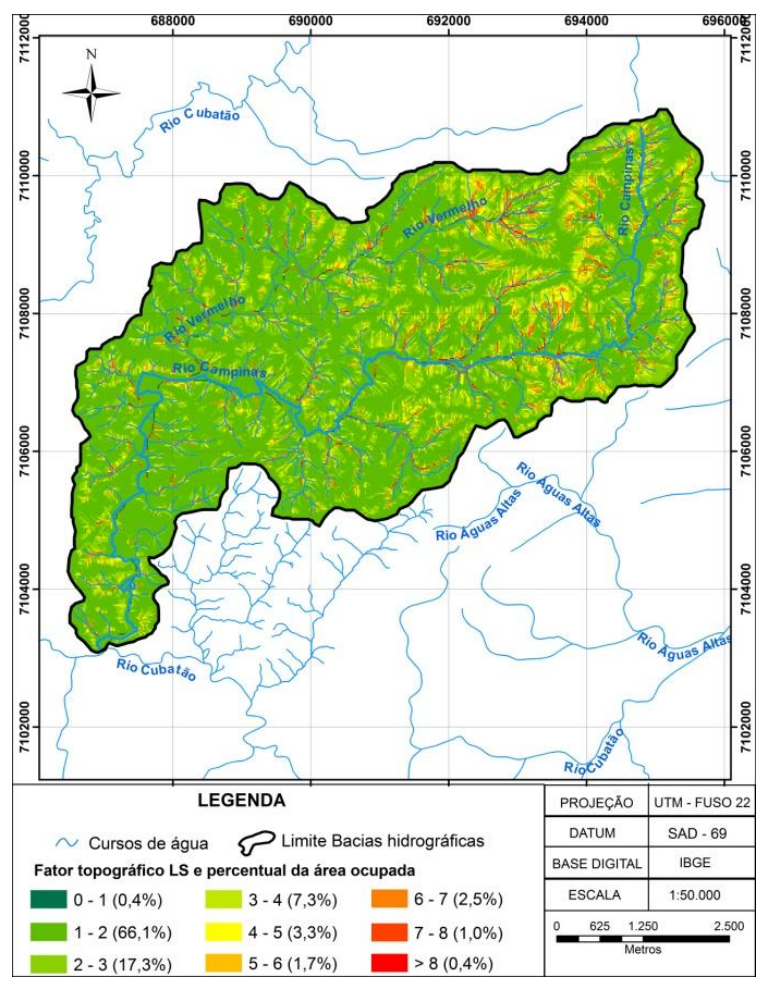

Figura 6: Mapa do fator topográfico (LS) na microbacia do Rio Campinas.

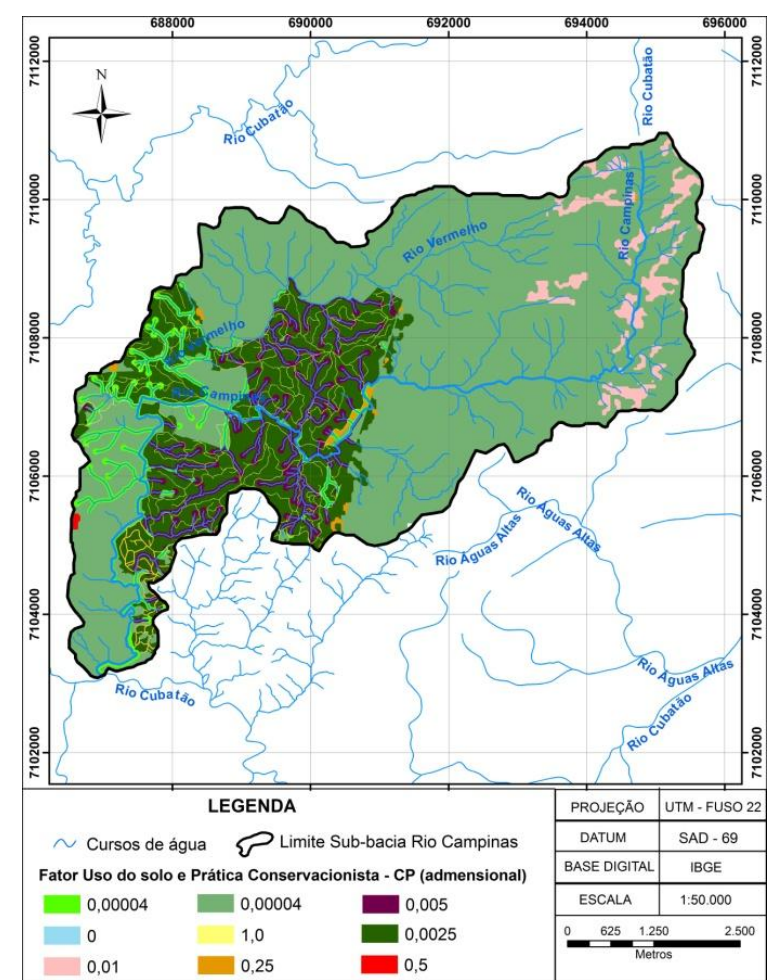

Figura 7: Mapa do fator uso do solo e práticas conservacionistas (CP) na microbacia do Rio Campinas.

Para as áreas alagáveis, áreas de FOD Montana e alto montana e APP preservada (ambas com floresta), campos de altitude, e capoeira foram atribuídos os valores para o Fator CP de 0,0,00004, 0,01 e 0,25 respectivamente, conforme valores empregados por Stein et al. (1987) e Oka-Fiori (2002). Já para o plantio de 
pinus e área de estradas, foram atribuídos os pesos de 0,0025 e 1,0, respectivamente (MARTINS, 2005 p.42; AVANZI, et al. 2008 p.565) (Figura 7).

Para a área urbanizada, grande parte dos trabalhos atribui pesos para o fator $\mathrm{CP}$ igual a 0 , tendo em vista que essas áreas geralmente apresentam grandes percentuais de áreas impermeabilizadas, e desta maneira, não expõe o solo aos processos erosivos. Porem, a classificação de áreas urbanas no presente estudo foi atrelada às áreas com alguma construção, mas que visualmente, na classificação das imagens, possuíam áreas de solo exposto. Portanto, como o CP de áreas com solo exposto é igual a 1, utilizou-se a média ponderada entre os pesos destas duas classes, que é 0,5. Para a classe de pinus em APP não foram encontrados valores para o fator CP nos trabalhos pesquisados. Para atribuir o peso para esta classe, tomou-se como base o peso da classe "plantio de pinus" acrescido um percentual de $100 \%$, já que se trata de uma área de fragilidade.

Os mapas dos fatores R, K, LS e CP foram aplicados na Equação Universal de Perda de Solo, resultando no mapa de erosão laminar, que expressa índices de perda média anual de solo por unidade de área na microbacia do Rio Campinas entre os anos de 2003 e 2005 (Figura 8). Os valores de perda de solo variaram de 0 a 355 ton.ha ${ }^{-1}$.ano ${ }^{-1}$, e foram divididos em 6 classes, conforme demonstra a Figura 8. 


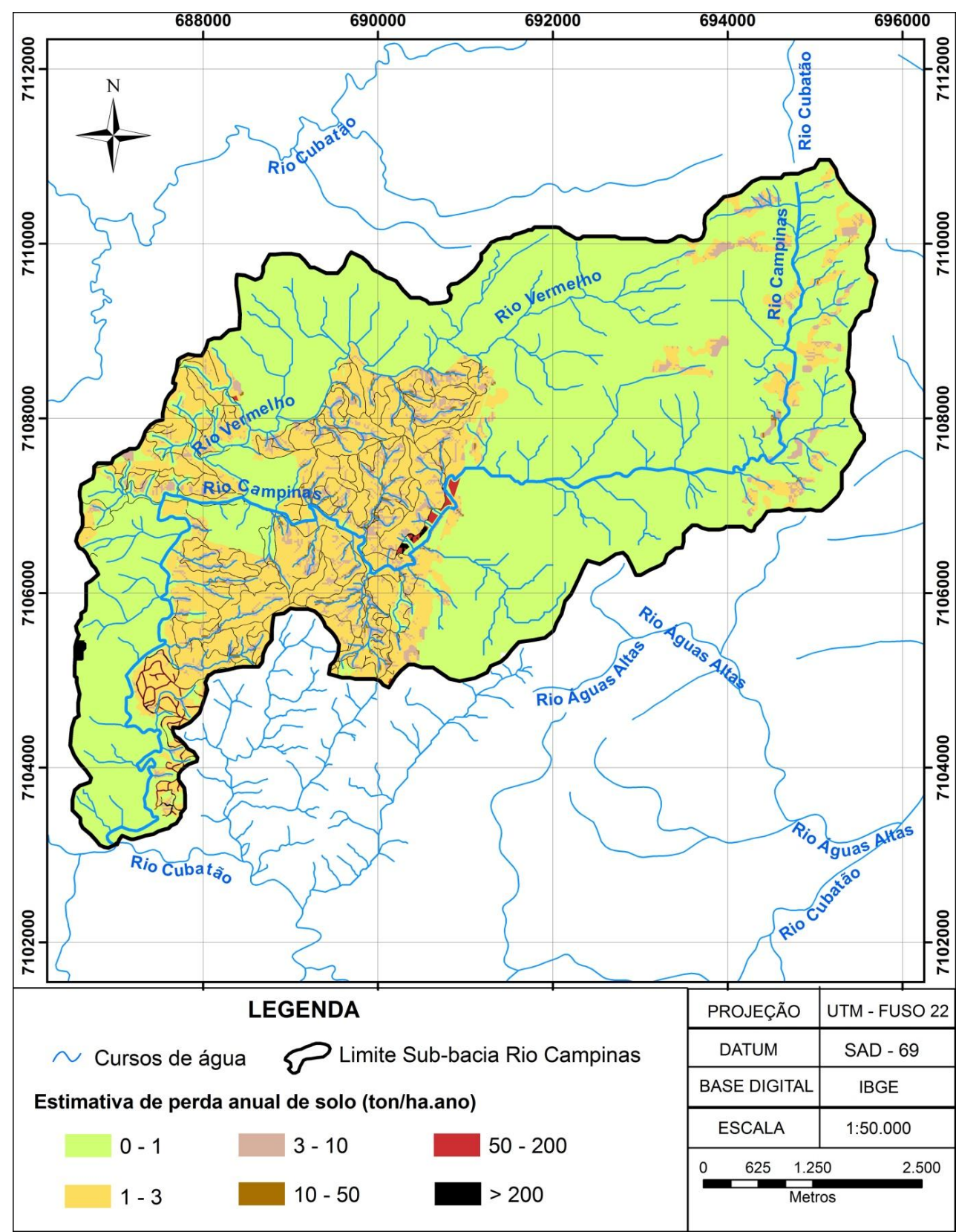

Figura 8: Mapa de estimativa de Perdas anuais de solo por erosão laminar das microbacias do Rio Campinas.

Apesar da área em estudo possuir característica de relevo com declives acentuados e grande ocorrência de argissolos, que possui alta suscetibilidade a erosão, a classe de perda de solo predominante foi de 0 a 1 ton.ha ${ }^{-1} \cdot$ ano $^{-1}$, abrangendo 2619,65 ha, o que equivale a $70,5 \%$ da área total da microbacia do Rio Campinas (Tabela 2). A área de ocorrência desta classe de perda de solo se estende, basicamente, sobre as áreas cobertas por florestas nativas, que representam 70,3\%. Neste caso, o fator uso do solo e práticas conservacionista (CP) 
foi o que mais contribuiu para a manutenção deste baixo índice de perdas médias anuais de solo, visto que esta classe ocorre tanto em áreas de argissolo quanto em cambissolos, e em grande amplitude de declividades.

Tabela 2: Relação de área das classes de perda anual de solo estimadas por meio da EUPS para a microbacia do Rio Campinas.

\begin{tabular}{ccccc}
\hline $\begin{array}{c}\text { Perdas de solo } \\
\left(\text { t.ha }^{-1} \text { ano }^{-1}\right)\end{array}$ & Área (ha) & Área (\%) & $\begin{array}{c}\text { Área } \\
\text { acumulada (\%) }\end{array}$ & Classes $^{*}$ \\
\hline $0-1$ & 2777,46 & 66,99 & 66,99 & Nenhuma ou ligeira \\
$1-3$ & 1065,26 & 25,69 & 92,69 & Nenhuma ou ligeira \\
$3-5$ & 120,61 & 2,91 & 95,60 & Nenhuma ou ligeira \\
$5-10$ & 66,18 & 1,60 & 97,19 & Nenhuma ou ligeira \\
$10-20$ & 19,19 & 0,46 & 97,66 & Moderada \\
$20-50$ & 2,70 & 0,07 & 97,72 & Moderada \\
$50-200$ & 19,49 & 0,47 & 98,19 & Alta \\
$>200$ & 74,92 & 1,81 & 100,00 & Muito alta \\
\hline
\end{tabular}

* Classificação segundo Food and Agriculture Organization - FAO (1967)

Observou-se também, nas áreas com produção de sedimento entre 0 a 1 t.ha ${ }^{1}$.ano ${ }^{-1}$, plantio de pinus sob Cambissolo Háplico Alumínico e pinus na APP e área urbanizada sob Argissolo Amarelo Alumínico em declives suaves (entre 0 a 3\%).

A segunda classe com maior expressividade ao longo do Rio Campinas é a de 1 a 3 t.ha ${ }^{-1}$.ano ${ }^{-1}$, compreendendo $22,8 \%$ da área total da microbacia, com predomínio de uso e ocupação do solo por reflorestamento de pinus e campos de altitude. O tipo de solo de maior ocorrência nesta classe foi o Argissolo Amarelo Distróficos, e a os pesos do fator topográfico variaram de 1 a 4 . Plantios de pinus em APP sob Cambissolo Háplico Alumínico também apresentaram perdas de solo entre 1 a 3 t.ha ${ }^{-1} \cdot$ ano $^{-1}$.

A classe de 3 a 10 t.ha $^{-1} \cdot$ ano $^{-1}$, distribuindo-se em $4,4 \%$ da área total da microbacia, está vinculada principalmente às áreas de plantio de pinus em APP e cobertas por capoeira em faixas de declividade entre $3-8 \%$ e $8-20 \%$, e as áreas de plantio de pinus e campos de altitude em Cambissolos Háplico Alumínico e faixas de declividade entre $20 \%$ e $75 \%$.

A classe de 10 a 50 t.ha $^{-1}$.ano ${ }^{-1}$ ocorre com menor expressividade $(0,5 \%)$, em manchas dispersas e descontínuas, associadas principalmente a pinus em APP, 
campos de altitude e capoeira em faixas de declives superiores a $75 \%$ e ocorrência de Argissolo Amarelo Distrófico. A classe de 50 a 200 t.ha $^{-1}$.ano ${ }^{-1}$ também apresenta-se com menor expressividade $(0,3 \%)$, porém de forma mais concentrada, em dois locais da microbacia do Rio Campinas. A primeira e mais concentrada mancha localiza-se na porção central da bacia, em uma área com vegetação em processo de regeneração, classificada como capoeira, desenvolvido sob Argissolo Amarelo Distrófico e declividades variando entre 0 a $45 \%$. A segunda porção desta classe localiza-se na região da foz do Rio Campinas, em áreas de estradas florestais (não pavimentadas), com pedologia predominante de Cambissolo Háplico Alumínico.

As áreas que apresentaram maiores perdas de solo na microbacia do Rio Campinas, superiores a 200 t.ha $^{-1} \cdot$ ano $^{-1}$, foram aquelas com características de uso de solo enquadradas como estradas florestais e áreas urbanizadas/solo exposto sob Argissolo Amarelo Distrófico, em grande amplitude de declividade, e áreas cobertas por capoeira, também em argissolos mas com declividades acentuadas, entre $20 \%$ a superior a $75 \%$.

Fazendo um balanço geral do mapa de erosão laminar, observa-se que 97,7\% da área da microbacia do Rio Campinas apresentaram estimativas de perdas anuais de solo entre 0 e 10 t.ha $^{-1}$.ano ${ }^{-1}$, o que segundo a classificação da Food and Agriculture Organization (FAO, 1967) representa nenhuma ou ligeira perda de solo. O grande percentual de florestas preservadas teve papel importante na manutenção destas baixas taxas de erosão. As áreas de plantio de pinus demonstraram potencial de perda anual de solo nesta faixa, entre 0 e 10 t.ha $^{-1} \cdot \mathrm{ano}^{-1}$, e as áreas que apresentaram maiores perdas de solo por erosão laminar foram, principalmente, as estradas florestais e áreas urbanizadas com solo exposto, independente das faixas de declividades, e capoeiras em declives acentuados, todas em domínio de Argissolo Amarelo Distrófico (Tabela 2).

Apesar do baixo potencial de perda de solo nas áreas ocupadas por plantio de pinus, faz-se necessário evidenciar que o mapa de perda de solo por erosão laminar (Figura 8) representa uma situação pontual, conforme classificação de uso e ocupação de solo com imagens de 2003 e 2005. Quando se avalia a dinâmica de uso e ocupação de uma área com atividades silviculturais, em um maior espaço de tempo, deve-se levar em consideração que estas áreas cobertas pelo plantio de 
pinus passarão por atividades de colheita, o que promoverá a exposição do solo aos processos erosivos, podendo alcançar índices de perdas de solo superiores a 200 t.ha ${ }^{-1} \cdot$ ano $^{-1}$, como observado nas áreas com classe de uso de solo urbanizado/solo exposto.

Portanto, em eventos de colheita florestal, é de imprescindível importância que se adotem medidas que diminua a área de solo exposto deixando os resíduos de colheita in loco, diminuindo o efeito do salpicamento pelas gotas de chuva e diminuindo a energia cinética do escoamento superficial, bem como o planejamento na utilização de maquinários, respeitando-se as faixas limites de declividades.

Oka-Fiori et al. (2004 p.93 a 98), avaliando a perda de solo na Bacia do Alto Paraguai no Pantanal matogrossense, para o ano de 1966, encontrou índices de perda média anual de solo por erosão laminar entre 0 e 50 t.ha $^{-1}$.ano ${ }^{-1}$, perda média de 0,37 tha $^{-1} \cdot$ ano $^{-1}$, período em que predominavam áreas de cerrado, com ocupação antrópica bastante restrita. Em consequência da rápida ocupação antrópica, principalmente com atividades agrícolas, os mesmos autores identificaram perdas médias de solo de 3,28 t.ha ${ }^{-1}$.ano ${ }^{-1}$ para o ano de 1985 e 3,10 t.ha ${ }^{-1}$.ano ${ }^{-1}$ para o ano de 1996. Silva et al. (2010 p.146), encontraram índices de perdas médias de solo para áreas de mata nativa de 0,39 t.ha $^{-1}$.ano-1, para plantio de eucalipto de 2,9 t.ha${ }^{1}$.ano ${ }^{-1}$, e para atividades que apresentam menores coberturas de solo, como a pastagem, plantio de cana e de milho, os valores encontrados foram, respectivamente, 3,86 t.ha ${ }^{-1}$.ano ${ }^{-1}, 32,5$ t.ha ${ }^{-1}$.ano ${ }^{-1}$ e 42 t.ha ${ }^{-1}$.ano ${ }^{-1}$. Estes resultados evidenciam a importância das áreas de cobertura florestais preservadas e a necessidades de adoção de práticas conservacionistas para minimizar a perda de degradação do solo.

As Áreas de Preservação Permanente irregulares, com plantio de pinus, apresentaram estimativa de perda de solo de ordem de 5 a 50 toneladas hectare ano, demonstrando maior suscetibilidade a erosão que as demais áreas de plantio de pinus. Estas áreas já se encontram em processo de conversão para florestas nativas, por meio de um plano de recuperação de áreas degradadas desenvolvido pela empresa responsável pela administração do empreendimento florestal.

Outro ponto crítico, com pouca expressividade espacial, mas com potencial elevado de perda de solo, se refere às estradas florestais, onde foram registradas 
taxas de erosão superiores a 200 t.ha ${ }^{-1}$.ano ${ }^{-1}$ nas áreas de ocorrência de Argissolo Amarelo Distrófico. A empresa que maneja o reflorestamento construiu caixas de contenção de enxurrada com distanciamento médio de 50 metros entre as caixas, variando com a declividade das estradas, com intuito de diminuir a energia cinética do escoamento superficial e promover a decantação de sedimento. Porém, é necessário que as manutenções dessas caixas de contenção sejam realizadas com freqüência, tendo em vista o grande potencial de perda de solo identificados neste trabalho.

\section{CONCLUSÕES}

A utilização do ArcGIS para a aplicação da Equação Universal de Perda de Solo (EUPS) por erosão laminar demonstrou-se bastante eficaz, e apresentou coerência com dados obtidos por outros autores que utilizaram outros software em ambiente SIG e métodos diretos. Para maior confiabilidade dos resultados obtidos neste estudo, a aplicação de métodos diretos e conferência de campo em trabalhos posteriores, além de uma classificação mais detalhada das tipologias de solo da microbacia do Rio Campinas seriam de grande importância.

97,7\% da superfície da microbacia do Rio Campinas apresentou nenhuma ou ligeira perda média anual de solo no período de 2003 a 2005. O grande percentual de áreas cobertas por floresta nativa foi responsável por manter as taxas de erosão entre 0 a 1 tha $^{-1}$.ano ${ }^{-1}$. As áreas de plantio de pinus apresentaram índices estimados de perda de solo entre 0 a 10 t.ha $^{-1} \cdot$ ano $^{-1}$, classificados como nenhuma ou ligeira perda de solo segundo FAO (1967).

As estradas florestais são áreas de grande risco de perda de solo, alcançando valores superiores a 200 t.ha $^{-1} \cdot$ ano $^{-1}$, e demandam, portanto, cuidados especiais quanto ao controle dos processos erosivos.

\section{REFERÊNCIAS}

AVANZI, C. J.; SILVA,M. L. N.; CURI, N.; MELLO, C. R. de; FONSECA, S.; Calibração e aplicação do modelo MUSLE em uma microbacia hidrográfica nos Tabuleiros Costeiros brasileiros. R. Bras. Eng. Agríc. Ambiental, v.12, n.6, p.563569, 2008. 
AZIM-ZADE, ZEMFIRA. GIS assessment of Pipeline corridor erosion along BakuTbilisi-Ceyhan route. Apresented in 23/fev/2010. Disponível em: <http://proceedings.esri.com/library/userconf/pug10/papers/gis

assessment_of_erosion_corridor.pdf> Acesso em: 22/out/2010.

BERTOL, I.; SCHICK, J.; BATISTELA, O.; LEITE, D.; AMARAL, A. J. Erodibilidade de um Cambissolo Húmico Alumínico Léptico, determinada sob chuva natural entre 1989 e 1998 em Lages (SC). R. Bras. Ci. Solo, 26:465-471, 2002.

BERTONI, J. \& LOMBARDI NETO, F. Conservação do solo, ícone. São Paulo, 335 p. 1990.

CAROLINO DE SÁ, M.A; LIMA, J.M. de; CURI, N.; MASSAROTO, J.A.; GRANATE DE SÁ, J. J; MARQUES, MELLO. Estimativa da erodibilidade pela desagregação por ultra-som e atributos de solos com horizonte B textural. Pesq. agropec. bras., Brasília, v.39, n.7, p.691-699, jul. 2004.

CAVICHIOLO, Sandra Regina. Perdas de solo e nutrientes por erosão hídrica em diferentes métodos de preparo do solo em plantios de Pinus taeda. (Tese apresentada ao Programa de Pós-Graduação em Engenharia Florestal, da Universidade Federal do Paraná) Curitiba - PR. 2005. 139 p.

CORREA, C. M. C.; ROLOFF, G.; SILVA, I. C.. Erosão real e estimada através da RUSLE em estradas florestais, em duas condições de solo e relevo e quatro perfis de solo. Scientia Forestalis, Piracicaba, n.76, p. 57-66, dez. 2007.

Food and Agriculture Organization F.A.O. 1967. La erosión del suelo por el água. Algunas medidas para combatirla en las tierras de cultivo. Cuadernos de fomento agropecuário da Org. de Las Naciones Unidas-FAO Roma, n. 81, 207 p.

GONÇALVES, M. L.; ZANOTELLI, C. T.; OLIVEIRA, F. A.. Diagnóstico e prognóstico das disponibilidades e demandas hídricas do Rio Cubatão do Norte - Joinville - Santa Catarina. Joinville, SC: UNIVILLE, 2006. 92 p.

HELFER, F. ; RISSO, Alfonso ; BELTRAME, Lawson Francisco de Souza ; MERTEN, Gustavo Henrique . Estimativa de Perda de Solo por Erosão Laminar na Bacia Hidrográfica do Rio Cuiabá Usando Técnicas de Geoprocessamento. In: XV Simpósio Brasileiro de Recursos Hídricos, 2003, Curitiba, PR. Anais do XV Simpósio Brasileiro de Recursos Hídricos. São Paulo, SP : 2003.

HILU, ANDREY. Erosão Hídrica na Bacia Hidrográfica do Rio Marumbi no Estado do Paraná, (Mestrado em Engenharia de Recursos Hídricos e Ambiental) Universidade Federal do Paraná - UFPR. Curitiba - PR, 2003 107p.

IBGE - INSTITUTO BRASILEIRO DE GEOGRAFIA E ESTATÍSTICA. DIRETORIA DE GEOCIÊNCIAS. DIVISÃO DE GEOCIÊNCIAS DO SUL. Reconhecimento de Solos (Folhas SG-22-Z-B-II e SG-22-Z-B-I). Florianópolis, IBGE, 2002. (escala $1: 100.000)$

LOMBARDI NETO, F.; BERTONI, J. Erodibilidade de solos paulistas. Campinas: Instituto Agronômico, 1975. 12p. (Boletim Técnico, 27).

LOMBARDI NETO, F.; MOLDENHAUER, W.C. Erosividade da chuva: sua distribuição e relação com as perdas de solo em Campinas (SP). Bragantia - 
Revista de Ciências Agronômicas - Instituto Agronômico, Campinas, v. 51, n. 2, p. 189-196, 1992

MANNINGEL, A. R.; CARVALHO, M. P.; MORETI, D.; MEDEIROS, L. R. Fator erodibilidade e tolerância de perda de solos do Estado de São Paulo. Acta Scientiarum. Maringá. V. 24, n. 5, p. 1335 - 1340, 2002.

MARTINS, S. G. Erosão hídrica em povoamento de eucalipto sobre os solos coesos nos Tabuleiros Costeiros, ES. (Doutorado em Agronomia) Lavras: UFLA, 2005, 106p.

OKA-FIORI, C.; FIORI, Alberto Pio; HASUI, Yociteru. Tolerância de Perdas de Solo na Bacia do Rio Itiquira, Mato Grosso, Brasil. Boletim Paranaense de Geociências, Curitiba, v. 54, n. 0, p. 83-99, 2004.

OKA-FIORI, C.; HASUI, Y. Geomorfologia e Dinâmica Temporo-Espacial da Bacia do Itiquira: Pantanal Matogrossense - MT, MS. (Doutorado apresentado ao Instituto de Geociências e Ciências Exatas de Rio Claro), UNESP/RIO CLARO, Brasil. 2002.

OKI, Viviana Kyoto. Impactos da Colheita de Pinus taeda sobre o Balanço Hídrico, Qualidade da Água e a Ciclagem de Nutrientes em Microbacias. (Dissertação - especialização em Ciências, Área de Concentração: Ciências Florestais) - Escola Superior de Agricultura "Luiz de Queiroz", Universidade de São Paulo, São Paulo. 2002. 71 p.

OLIVEIRA, Fabiano A. Estudo do Aporte Sedimentar em Suspensão na Baía da Babitonga sob a Ótica da Geomorfologia, (Doutorado em Geografia Física) Departamento de Geografia da Faculdade de Filosofia, letras e Ciências Humanas da Universidade de São Paulo São Paulo - USP, 2006 286p.

RENARD, K.G.; FOSTER, G.A.; WEESIES, G.A.; McCOLL, D.K. (1997) Predicting Soil Erosion by Water: A Guide to Conservation Planning with the Revised Universal Soil Loss Equation (RUSLE). Washington: U.S.D.A., 440p. (Agriculture Handbook n. 703.)

SANTOS, G. G.; GRIEBELER, N. P.; OLIVEIRA, L. F. C. Chuvas intensas relacionadas à erosão hídrica. R. Bras. Eng. Agric. Ambiental. v.14, n.2, p. 115123, 2010.

SILVA, V. C. da. Cálculo automático do fator topográfico (LS) da EUPS, na Bacia do Rio Paracatu. Pesquisa Agropecuária Tropical, 33 (1): 29-34, 2003

SILVA, F. G. B.; MINOTTI, R. T.; NETO, F. L.; CRESTANA, S. Previsão da perda de solo na Fazenda Canchim - SP (EMBRAPA) utilizando geoprocessamento e o USLE 2D. Eng Sanit Ambient. v.15, n.2, abr/jun 2010. pg 141-148

VALE JÚNIOR, J. F. ; BARROS, L. S. ; SOUSA, M. I. L. ; Sandra Cátia Pereira UCHOA, . Erodibilidade e suscetibilidade à erosão dos solos de cerrado com plantio de Acacia Mangium em Roraima. Agro@mbiente On-line, v. 3, p. 1-8, 2009.

WISCHMEIER, W.H. \& SMITH, D.D. Rainfall energy and its relationship to soil loss. Trans. Am. Geophys. Union, 39:285-291, 1965 